\title{
A New Prediction Method of Rockburst in Underground Engineering Based on Elastic Energy Index
}

\author{
SC. Xu $u^{1,2, a}$ SS. Yu ${ }^{3, b}$
}

${ }^{1}$ State Key Laboratory of Geomechanics and Geotechnical Engineering, Institute of Rock and Soil Mechanics, Chinese Academy of Science,.Wuhan, Hubei430071, China

${ }^{2}$ School of architecture and Civil Engineering, Shenyang University, Shenyang, Liaoning 110044 , ChinaKey Laboratory of Liaoning Province for environmental geotechnical engineering, Shenyang, Liaoning 110044, China

${ }^{3}$ Liaoning Administration of Coal Mine Safety, Shenyang, Liaoning 110042, China

axusuchao@163.coml, byuss_007@163.com

Keywords: prediction method, rockburst, elastic energy Index.

Abstract: In this paper, a new prediction method of rockburst in underground engineering has been proposed based on elastic energy index through cyclic loading and unloading test. The calculation formula has been explicitly explained and $\mathrm{W}_{\mathrm{ET}}$ was gained through cyclic loading and unloading test result. Finally, we obtain the conclusion that skarn is a kind of hard brittle rock which has high rock burst tendency. In the cyclic loading and unloading test, the curve behaviors as a " $n$ " shapke which indicate that its energy storage capacity increase first with cycle times and decrease after reaching peak point.

\section{Introduction}

Generally speaking, the surrounding rock have to bear cyclic variation of stress in the process of room and pillar mining. And it is absolutely the cause of some hard brittle geological disaster. So in order to figure out the mechanism of such failure and prevent it in time, it is urgent to get into research of a new prediction method and we need to analyze the loading process of rock from energy point of view. Although researcher has done plenty of works on this problem, ${ }^{[1-7]}$ however there is still lots of work to do. In this paper, we first give an introduction of Elastic energy index. Then, Energy Dissipation Process in Unloading Test is deeply explained. Finally, we give the Rockburst Tendency Analysis of skarn and obtain some beneficial conclusions.

\section{Introduction of Elastic energy index}

Elastic energy index is a kind of classification index of rock burst tendency which is propsed by Kidybinski in 1981.This index could be calculated by unloading test. Firstly, carried out the loading test to mean failure load of $75 \%$ - $85 \%$, then unload to mean failure load of $1 \%-5 \%$, the unloading process in the release of elastic strain energy and the consumption of plastic strain energy ratio is elastic energy index. The rock failure process release more energy if $\mathrm{W}_{\mathrm{ET}}$ is a high value.

Formula:

$$
W_{E T}=E_{e} / E_{p}
$$

$W_{E T}$ : Elastic energy index

$E_{e}$ : Elastic strain energy

$E_{p}$ : Plastic strain energy

The rock burst tendency of $\mathrm{W}_{\mathrm{ET}}$ :

$$
\begin{array}{lc}
W_{e t}<2.0, & \text { slightly } \\
2.0 \leq W_{e t}<5, & \text { moderately } \\
W_{e t} \geq 5, & \text { strongly }
\end{array}
$$




\section{Energy Dissipation Process in Unloading Test}

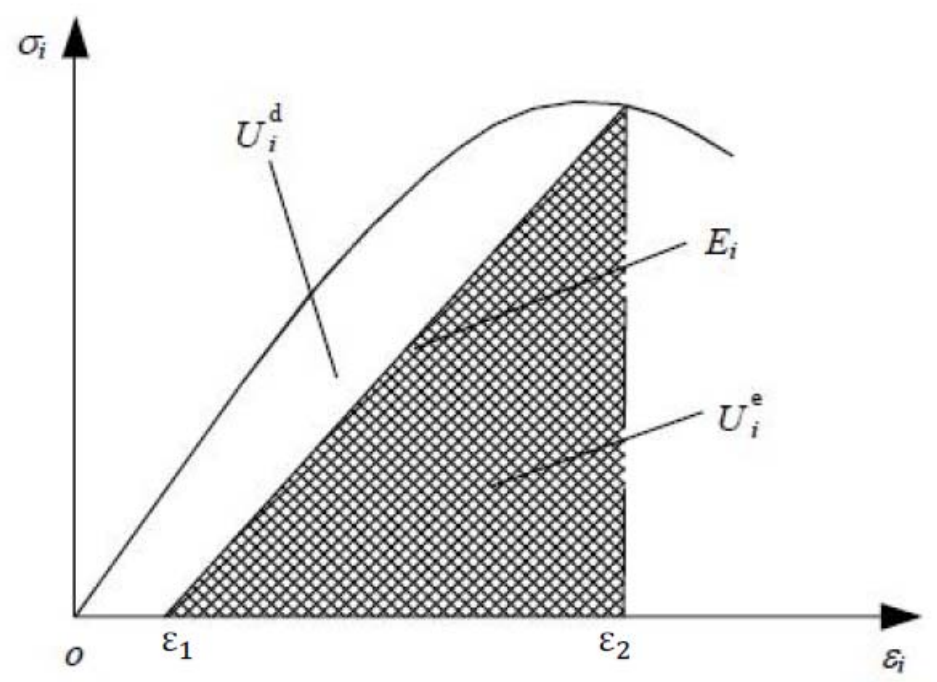

Figure.1 The relationship between $\mathrm{U}_{\mathrm{e}}$ and $\mathrm{U}_{\mathrm{d}}$

$$
\begin{aligned}
& \mathrm{U}^{\mathrm{e}}=\int_{\varepsilon^{1}}^{\varepsilon^{2}} \sigma_{\mathrm{i}} \mathrm{d} \varepsilon_{\mathrm{i}} \\
& \mathrm{U}^{\mathrm{d}}=\int_{0}^{\varepsilon^{2}} \sigma_{\mathrm{i}} \mathrm{d} \varepsilon_{\mathrm{i}}-\int_{\varepsilon^{1}}^{\varepsilon^{2}} \sigma_{\mathrm{i}} \mathrm{d} \varepsilon_{\mathrm{i}}
\end{aligned}
$$

The relationship between $U_{e}$ and $U_{d}$ is shown as figure2. The calculating methods of $U^{e}$ and $U^{d}$ are shown as equation (1) and (2). In these equations, $U_{e}$ and $U_{d}$ represent elastic energy and plastic energy respectively. Generally speaking, the dissipated energy $\left(\mathrm{U}^{\mathrm{e}}\right)$ could be in such forms as surface energy, thermal energy and even electromagnetic energy ${ }^{[9]}$. It is a characterizationof the inner damage and also a measurement of the deterioration extent. In the loading process, the elastic energy was stored in samples as a capacity index of absorbing energy before peak strength. It could be released with the stress decreased and strain rehabilitation without encroaching the limited capacitance. Thus, the ratio of $\mathrm{U}^{\mathrm{d}}$ in $\mathrm{U}$ is a key controlling fact for the stability and capacity of samples.

\section{Rockburst Tendency Analysis}

According to the calculation method of elastic energy index, skarn belongs to the rock with strong rock burst tendency due to the result of uniaxial and unloading test which $\mathrm{W}_{\mathrm{ET}}$ is 5.6. Due to the rock from the room and pillar mining of metal mines have to go through loading and unloading process in the exploitation of actual working condition. So, it is necessary to keep an eye on the elastic energy index during the circulation of loading and unloading process. The elastic energy index variation of skarn is shown in figure 2.6. 


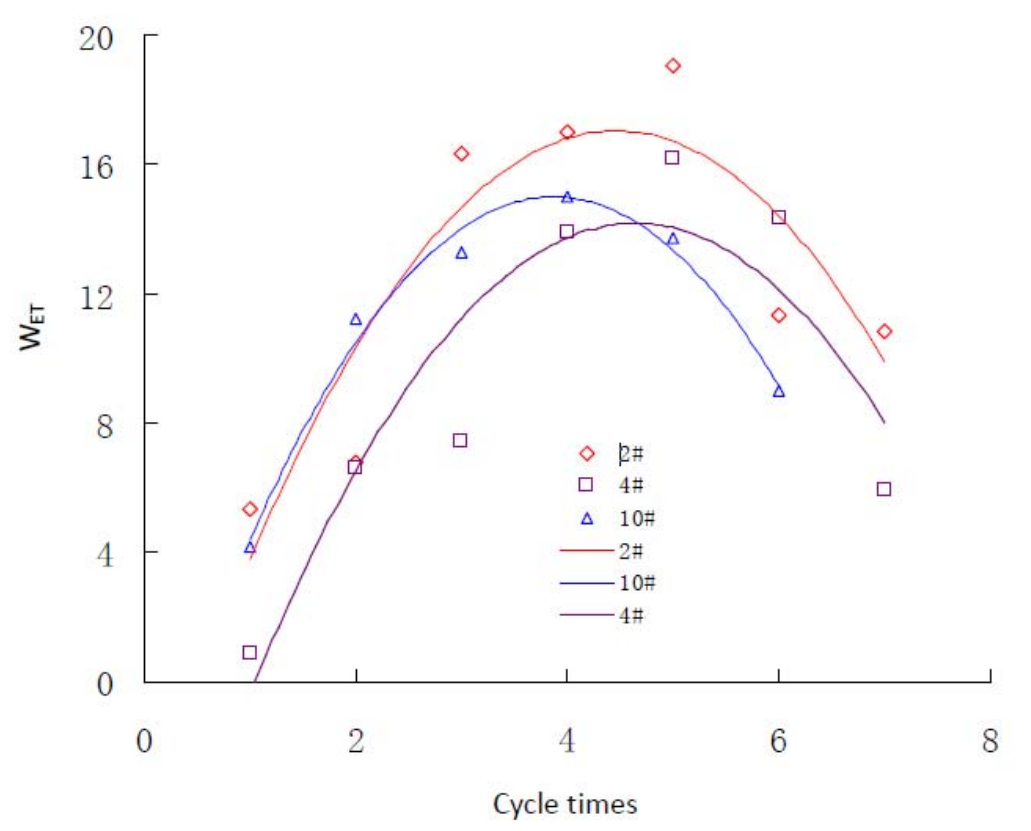

Figure.2 The relationship between $\mathrm{W}_{\mathrm{ET}}$ and cyclic times

It can be seen in above figure that elastic energy index falls within the scope of strong rock burst in the second circulation according to the elastic energy index criterion. And in the whole cycle process, elastic energy index of skarn increased along with the cycling times first then decreases, and the average peak value reached 15 which belong to the scope of strong rock burst. So we can firmly come to the conclusion that skarn is a kind of hard brittle rock which has high rock burst tendency. In the cyclic loading and unloading test, the curve behaviors as a " $n$ " shapke which indicate that its energy storage capacity increase first with cycle times and decrease after reaching peak point.

\section{Conclusions and Acknowlegement}

Elastic energy index is a kind of classification index of rock burst tendency. Skarn in this project is a kind of hard brittle rock which has high rock burst tendency. In the cyclic loading and unloading test, the curve behaviors as a " $n$ " shapke which indicate that its energy storage capacity increase first with cycle times and decrease after reaching peak point. This paper get financial support from the national natural science foundation of China(51304138).

\section{Reference:}

[1].Yang-Shengqi, Xu-Weiya, Su-Chengdong. Study on the deformation failure and energy properties of marble specimen under triaxial compression[J]. Engineering Mechanics, 2007, 24(1): 136-142.

[2]. Xu-Suchao, FENG-Xiating, CHEN-Bingrui.Experimental study of skarn under uniaxial cyclic loading and unloading tests and acoustic emission characteristics [J]. Rock and Soil Mechanics, 2009, 30(10): 2929-2934.

[3]. Xu-Suchao, FENG-Xiating, CHEN-Bingrui. Acoustic emission characteristics and strength variation of skarn under true triaxial test.[J]. Rock Mechanics: Achievements and Ambitions. 2011, 215-218. 
[4]. Xu-Suchao, CHEN-Bingrui, Jin-Changyu. Study on the Prediction Method for Brittle Failure of Hard Rock Based on Acoustic Emission Test [J]. Advanced Materials Research. Volumes 594 597.

[5]. Yu-Yong, Zhang-Zongxian, Yu-Jie. Energy dissipation and damage characters in rock direct tensile destruction[J]. Chinese Journal of Rock Mechanics and Engineering, 1998, 17(4): 386-392.

[6].You-Mingqing, Hua-Anzeng. Energy analysisof failure process of rock specimens[J]. Chinese Journal of Rock Mechanics and Engineering, 2002, 21(6): 778-781.

[7].Chen-Weizhong, Lu-Senpeng, Guo-Xiaohong. Research on unloading confining pressure tests and rock burst criterion based on energy theory[J]. Chinese Journal of Rock Mechanics and Engineering, 2009, 28(8): 1 530-1 540.

[8].Xie-Heping, JU-Yang, LI-Liyun. Criteria for strength and structural failure of rocks based on energy dissipation and energy release principles[J]. Chinese Journal of Rock Mechanics and Engineering, 2005, 24(17): 3003-3010.

[9]. Xie-Heping, JU-Yang, LI-Liyun. Energy mechanism of deformation and failure of rocks[J]. Chinese Journal of Rock Mechanics and Engineering, 2008, 27(9): 1 729-1 739. 